\title{
The dynamics of concentration of selected chemical components of rainfalls in the Miedzyzdroje
}

\section{Dynamika stężenia wybranych składników chemicznych w opadach atmosferycznych na terenie miasta Międzyzdroje}

\author{
Piotr Daniszewski \\ Katedra Zoologii Bezkręgowców i Limnologii \\ Wydział Biologii, Uniwersytet Szczeciński \\ ul. Wąska 13, 71-415 Szczecin, Poland \\ E-mail address: daniszewski@univ.szczecin.pl
}

\begin{abstract}
The development of a business man and also growing up processes the transformative environment adversely affect the individual elements of the natural environment. These processes they realize that individual elements of environmental protection becomes the basis for the further development of socio-economic background. In recent years the increasing pollution of the atmosphere causes more and more interest in the science of the substances contained in it and merge back to the surface of the Earth. Of great importance for the environment have the substances contained in the water drainage, as in the form of dissolved very easily reach the individual environmental elements causing their contamination. Research was carried out in the years 2008-2011 (January-December) in the town of Miedzyzdroje. In the tests was measured the amount of precipitation, chemical composition $\left(\mathrm{NH}_{4}{ }^{+}, \mathrm{NO}_{3}{ }^{-}, \mathrm{PO}_{4}{ }^{3-}\right.$ - ions were numbered), $\mathrm{pH}$ and conductivity. Międzyzdroje is a city located in the north-western part of the county on the island of Wolin on the Baltic Sea. The city is located on the Bay of Pomorska, in the central part of the coast of the island of Wolin. Part of the East of Międzyzdroje is situated on the western slopes of the remains of the Beautiful. The climate of the island of Wolin is different from the rest of the country because the climate is strongly influenced by the presence of the Baltic Sea. It is characterized by high humidity, sunlight and precipitation variability, wind direction and force large diurnal temperature amplitude. Międzyzdroje is a resort and tourist destination.
\end{abstract}

Keywords: wet the fallout of atmospheric pollutants; $\mathrm{pH}$; concentration of chemical components; the amount of precipitation 


\section{STRESZCZENIE}

Rozwój działalności gospodarczej człowieka a także nasilające sie procesy przekształcające środowisko naturalne wpływają niekorzystnie na poszczególne elementy środowiska przyrodniczego. Procesy te uświadamiają nam, że ochrona poszczególnych elementów środowiska przyrodniczego staje się podstawą dla dalszego rozwoju społeczno - ekonomicznego. Występujące w ostatnich latach zwiększające się zanieczyszczenie atmosfery powoduje coraz większe zainteresowanie nauki ilością substancji znajdujących się w niej oraz doprowadzanych z powrotem na powierzchnię ziemi. Duże znaczenie dla środowiska naturalnego mają substancje zawarte w wodzie opadowej, gdyż w postaci rozpuszczonej bardzo łatwo docierają do poszczególnych elementów środowiska przyrodniczego powodując ich zanieczyszczenie. Badania prowadzono w latach 2008 - 2011 (styczeń - grudzień) na terenie miasta Międzyzdroje. W badaniach mierzono wysokość opadu, skład chemiczny (oznaczano jony $-\mathrm{NH}_{4}{ }^{+}, \mathrm{NO}_{3}^{-}, \mathrm{PO}_{4}{ }^{3-}$ ) oraz odczyn $\mathrm{pH}$ i przewodnictwo. Międzyzdroje jest to miasto położone $\mathrm{w}$ północno-zachodniej części województwa zachodniopomorskiego na wyspie Wolin nad Morzem Bałtyckim. Miasto położone jest nad Zatoką Pomorską, w środkowej części wybrzeża wyspy Wolin. Część wschodnia Międzyzdrojów leży na zachodnich stokach morenowego Pasma Wolińskiego. Klimat wyspy Wolin jest różny od klimatu reszty kraju, ponieważ jest silnie kształtowany obecnością Morza Bałtyckiego. Charakteryzuje go duża wilgotność powietrza, zmienność nasłonecznienia i rozkładu opadów atmosferycznych, siły kierunku wiatru oraz duże dobowe amplitudy temperatur. Międzyzdroje są ośrodkiem wypoczynkowym i turystycznym.

Stowa kluczowe: mokry opad zanieczyszczeń atmosferycznych, $\mathrm{pH}$, stężenie składników chemicznych, wysokość opadów

\section{WPROWADZENIE}

Rozwój działalności gospodarczej człowieka a także nasilające sie procesy przekształcające środowisko naturalne wpływają niekorzystnie na poszczególne elementy środowiska przyrodniczego [1-3, 5-9, 10, 22-24]. Procesy te uświadamiają nam, że ochrona poszczególnych elementów środowiska przyrodniczego staje się podstawą dla dalszego rozwoju społeczno - ekonomicznego [1, 2, 7,9].

Występujące w ostatnich latach zwiększające się zanieczyszczenie atmosfery powoduje coraz większe zainteresowanie nauki ilością substancji znajdujących się w niej oraz doprowadzanych z powrotem na powierzchnię ziemi [1, 3, 4, 18, 22-24]. Duże znaczenie dla środowiska naturalnego mają substancje zawarte w wodzie opadowej, gdyż w postaci rozpuszczonej bardzo łatwo docierają do poszczególnych elementów środowiska przyrodniczego powodując ich zanieczyszczenie [1, 3, 4, 18, 22-24].

Celem pracy było określenie wysokości opadu atmosferycznego, składu chemicznego (oznaczano jony - $\mathrm{NH}_{4}^{+}, \mathrm{NO}_{3}^{-}, \mathrm{PO}_{4}{ }^{3-}$ ) oraz odczynu $\mathrm{pH}$ i przewodnictwa.

\section{CZĘŚĆ DOŚWIADCZALNA}

Badania prowadzono w latach 2008 - 2011 (styczeń - grudzień) na terenie miasta Międzyzdroje. Międzyzdroje jest to miasto położone w północno-zachodniej części województwa zachodniopomorskiego na wyspie Wolin nad Morzem Bałtyckim.

Miasto położone jest nad Zatoką Pomorską, w środkowej części wybrzeża wyspy Wolin. Część wschodnia Międzyzdrojów leży na zachodnich stokach morenowego Pasma Wolińskiego.

Klimat wyspy Wolin jest różny od klimatu reszty kraju, ponieważ jest silnie kształtowany obecnością Morza Bałtyckiego. Charakteryzuje go duża wilgotność powietrza, 
zmienność nasłonecznienia i rozkładu opadów atmosferycznych, siły kierunku wiatru oraz duże dobowe amplitudy temperatur. Międzyzdroje są ośrodkiem wypoczynkowym i turystycznym.

$\mathrm{Na}$ mapie nr 1 przedstawiono usytuowanie punktu pomiarowego na terenie miasta Międzyzdroje.

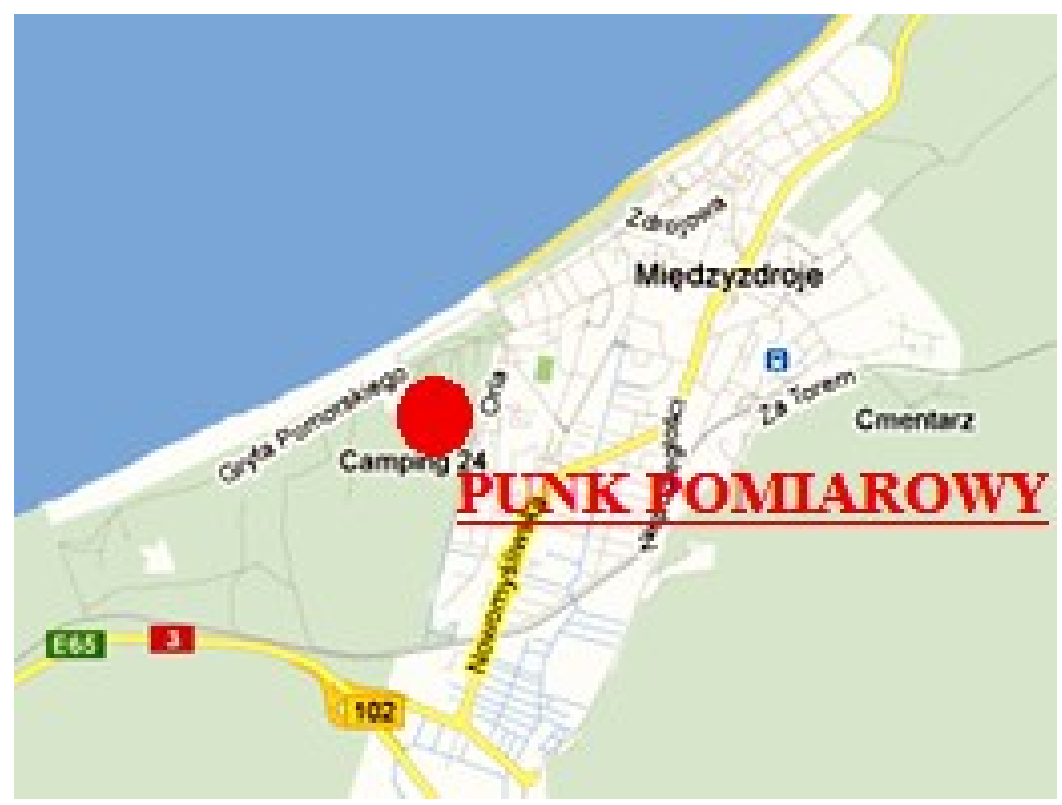

Mapa 1. Usytuowanie punktu pomiarowego w Międzyzdrojach. Źródto: Google map 2012/ Opracowanie wtasne

Przy lokalizacji punktu pomiarowego, wyborze rodzaju chwytaczy opadów atmosferycznych oraz sposobu poboru prób wody opadowej kierowano się wytycznymi zawartymi w Polskiej Normie PN - 91C - 04642/02 [25].

Próby z kolektorów opadów były zbierane jako opad całkowity i opad mokry. Próby zbierano w cyklu dobowym. Wielkość opadu atmosferycznego była mierzona za pomocą deszczomierza Hellmanna (jest to deszczomierz do mierzenia opadów atmosferycznych deszczu i śniegu.

Pobór próbek prowadzono systemem dobowym. Metodykę przeprowadzonych oznaczeń chemicznych oparto na opracowaniu Hermanowicza i in. (1999).

$\mathrm{W}$ niniejszej pracy oznaczono stężenie $\mathrm{NH}_{4}{ }^{+}$- zgodnie $\mathrm{z} \mathrm{PN} / \mathrm{C}-04576.01, \mathrm{NO}_{3}{ }^{-}{ }^{-}$ zgodnie $\mathrm{z}$ PN/C-04576.09, $\mathrm{PO}_{4}{ }^{3-}$ - zgodnie $\mathrm{z}$ PN/C-04537.02.

\section{WYNIKI POMIARÓW I DYSKUSJA}

Rozkład wielkości opadów atmosferycznych na terenie miasta Międzyzdroje oraz średnie miesięczne i roczne wartości ich parametrów fizyko-chemicznych przedstawiono w tabelach $1-4$. 
Tabela 1. Średnie miesięczne i roczna wielkość opadu atmosferycznego (w mm) oraz parametrów fizyko-chemicznych wód opadowych w 2008 roku

Table 1. Mean monthly and annual precipitation (in $\mathrm{mm}$ ) and physico-chemical parameters of precipitation in 2008

\begin{tabular}{|c|c|c|c|c|c|c|c|}
\hline \multirow{2}{*}{ Miesiąc } & \multicolumn{2}{|c|}{ Opad } & \multirow{2}{*}{ pH } & \multirow{2}{*}{$\frac{\text { Przewodnictwo }}{\mu \mathrm{S}^{-1} \mathrm{~cm}^{-1}}$} & \multirow{2}{*}{$\frac{\mathrm{NO}_{\mathbf{3}}{ }^{-}}{\mathrm{mgN} \mathrm{dm}^{-3}}$} & \multirow{2}{*}{$\frac{\mathbf{N H}_{\mathbf{4}}{ }^{+}}{\mathrm{mgN}^{\prime} \mathrm{dm}^{-3}}$} & \multirow{2}{*}{$\frac{\mathbf{P O}_{4}{ }^{3-}}{\mathrm{mg} \mathrm{PO}_{4} \mathrm{dm}^{-3}}$} \\
\hline & $\mathrm{mm}$ & dni & & & & & \\
\hline Styczeń & 37,8 & 23 & 4,82 & 27,21 & 0,416 & 0,298 & 0,026 \\
\hline Luty & 32,3 & 17 & 4,85 & 29,36 & 0,472 & 0,325 & 0,030 \\
\hline Marzec & 39,7 & 25 & 5,17 & 24,18 & 0,281 & 0,241 & 0,017 \\
\hline Kwiecień & 42,9 & 15 & 5,24 & 25,62 & 0,162 & 0,168 & 0,012 \\
\hline Maj & 49,3 & 7 & 5,26 & 26,17 & 0,124 & 0,129 & 0,010 \\
\hline Czerwiec & 58,2 & 13 & 5,32 & 23,74 & 0,098 & 0,138 & 0,010 \\
\hline Lipiec & 75,9 & 11 & 5,36 & 18,29 & 0,095 & 0,107 & 0,011 \\
\hline Sierpień & 68,3 & 12 & 5,41 & 15,32 & 0,102 & 0,103 & 0,010 \\
\hline Wrzesień & 50,3 & 19 & 5,52 & 13,50 & 0,094 & 0,095 & 0,010 \\
\hline Październik & 56,3 & 15 & 5,37 & 16,82 & 0,112 & 0,118 & 0,015 \\
\hline Listopad & 45,8 & 17 & 5,28 & 20,46 & 0,154 & 0,138 & 0,017 \\
\hline Grudzień & 48,1 & 16 & 4,92 & 23,74 & 0,268 & 0,218 & 0,021 \\
\hline \multicolumn{3}{|c|}{ Średnia } & 5,21 & 22,03 & 0,185 & $\mathbf{0 , 1 7 3}$ & 0,016 \\
\hline Razem 2008 & 604,9 & 190 & & & - & & \\
\hline
\end{tabular}

Tabela 2. Średnie miesięczne i roczna wielkość opadu atmosferycznego (w mm) oraz parametrów fizyko-chemicznych wód opadowych w 2009 roku

Table 2. Mean monthly and annual precipitation (in $\mathrm{mm}$ ) and physico-chemical parameters of

\begin{tabular}{|c|c|c|c|c|c|c|c|}
\hline \multirow{2}{*}{ Miesiąc } & \multicolumn{2}{|c|}{ Opad } & \multirow{2}{*}{$\mathbf{p H}$} & \multicolumn{2}{|c|}{\begin{tabular}{l|l} 
Przewodnictwo & $\mathrm{NO}_{3}^{-}$
\end{tabular}} & \multirow{2}{*}{$\frac{\mathbf{N H}_{4}{ }^{+}}{\mathrm{mgN} \cdot \mathrm{dm}^{-3}}$} & \multirow{2}{*}{$\frac{\mathbf{P O}_{4}{ }^{\mathbf{3 -}}}{\mathrm{mg} \mathrm{PO}_{4} \cdot \mathrm{dm}^{-3}}$} \\
\hline & $\mathrm{mm}$ & dni & & $\mu \mathrm{S} \mathrm{cm}^{-1}$ & $\mathrm{mgN} \cdot \mathrm{dm}^{-3}$ & & \\
\hline Styczeń & 38,3 & 24 & 4,91 & 26,41 & 0,408 & 0,289 & 0,025 \\
\hline Luty & 34,1 & 18 & 4,86 & 28,63 & 0,453 & 0,307 & 0,030 \\
\hline Marzec & 37,8 & 26 & 5,21 & 25,17 & 0,238 & 0,242 & 0,023 \\
\hline Kwiecień & 43,1 & 16 & 5,19 & 27,05 & 0,211 & 0,172 & 0,015 \\
\hline $\mathrm{Maj}$ & 47,4 & 10 & 5,26 & 23,71 & 0,157 & 0,130 & 0,012 \\
\hline Czerwiec & 58,2 & 13 & 5,38 & 17,82 & 0,073 & 0,115 & 0,010 \\
\hline Lipiec & 65,7 & 12 & 5,41 & 15,27 & 0,056 & 0,103 & 0,012 \\
\hline Sierpień & 60,8 & 11 & 5,58 & 14,60 & 0,082 & 0,078 & 0,011 \\
\hline Wrzesień & 52,6 & 18 & 5,63 & 15,84 & 0,070 & 0,064 & 0,010 \\
\hline Październik & 53,7 & 15 & 5,50 & 18,36 & 0,136 & 0,094 & 0,014 \\
\hline Listopad & 47,2 & 16 & 5,46 & 19,62 & 0,169 & 0,136 & 0,018 \\
\hline Grudzień & 49,1 & 17 & 5,08 & 23,06 & 0,279 & 0,189 & 0,023 \\
\hline \multicolumn{3}{|c|}{ Średnia } & 5,29 & 19,81 & 0,194 & 0,160 & $\mathbf{0 , 0 1 7}$ \\
\hline Razem 2009 & 588,0 & 196 & \multicolumn{5}{|c|}{ - } \\
\hline
\end{tabular}


Tabela 3. Średnie miesięczne i roczna wielkość opadu atmosferycznego (w mm) oraz parametrów fizyko-chemicznych wód opadowych w 2010 roku

Table 3. Mean monthly and annual precipitation (in $\mathrm{mm}$ ) and physico-chemical parameters of precipitation in 2010

\begin{tabular}{|c|c|c|c|c|c|c|c|}
\hline \multirow{2}{*}{ Miesiąc } & \multicolumn{2}{|c|}{ Opad } & \multirow{2}{*}{$\mathbf{p H}$} & \multirow{2}{*}{\begin{tabular}{|c|} 
Przewodnictwo \\
$\mu \mathrm{S}^{-1} \mathrm{~cm}^{-1}$
\end{tabular}} & \multirow{2}{*}{$\frac{\mathrm{NO}_{\mathbf{3}}{ }^{-}}{\mathrm{mgN} \cdot \mathrm{dm}^{-3}}$} & \multirow{2}{*}{$\frac{\mathbf{N H}_{4}^{+}}{\mathrm{mgN}^{+} \mathrm{dm}^{-3}}$} & \multirow{2}{*}{$\frac{\mathbf{P O}_{4}{ }^{3-}}{\mathrm{mg} \mathrm{PO}_{4} \mathrm{dm}^{-3}}$} \\
\hline & $\mathrm{mm}$ & dni & & & & & \\
\hline Styczeń & 40,8 & 24 & 4,92 & 24,71 & 0,374 & 0,286 & 0,025 \\
\hline Luty & 34,6 & 17 & 5,11 & 26,85 & 0,340 & 0,308 & 0,028 \\
\hline Marzec & 38,5 & 25 & 5,17 & 22,69 & 0,251 & 0,240 & 0,017 \\
\hline Kwiecień & 45,1 & 16 & 5,27 & 25,04 & 0,174 & 0,169 & 0,010 \\
\hline Maj & 50,7 & 8 & 5,31 & 19,82 & 0,136 & 0,118 & 0,011 \\
\hline Czerwiec & 53,8 & 12 & 5,40 & 18.04 & 0,119 & 0,096 & 0,011 \\
\hline Lipiec & 80,2 & 12 & 5,53 & 13,25 & 0,093 & 0,086 & 0,012 \\
\hline Sierpień & 75,3 & 15 & 5,62 & 14,73 & 0,074 & 0,062 & 0,010 \\
\hline Wrzesień & 42,8 & 17 & 5,68 & 15,92 & 0,082 & 0,070 & 0,012 \\
\hline Październik & 52,6 & 16 & 5,40 & 16,70 & 0,129 & 0,098 & 0,017 \\
\hline Listopad & 47,2 & 16 & 5,51 & 19,02 & 0,158 & 0,117 & 0,016 \\
\hline Grudzień & 45,9 & 17 & 5,24 & 23,16 & 0,236 & 0,197 & 0,020 \\
\hline \multicolumn{3}{|c|}{ Średnia } & 5,35 & 19,99 & 0,180 & 0,144 & 0,016 \\
\hline Razem 2010 & 607,5 & 195 & \multicolumn{5}{|c|}{ - } \\
\hline
\end{tabular}

Tabela 4. Średnie miesięczne i roczna wielkość opadu atmosferycznego (w mm) oraz parametrów fizyko-chemicznych wód opadowych w 2011 roku

Table 4. Mean monthly and annual precipitation (in $\mathrm{mm}$ ) and physico-chemical parameters of precipitation in 2011

\begin{tabular}{|c|c|c|c|c|c|c|c|}
\hline \multirow{2}{*}{ Miesiąc } & \multicolumn{2}{|c|}{ Opad } & \multirow{2}{*}{ pH } & \multirow{2}{*}{$\begin{array}{c}\text { Przewodnictwo } \\
\mathrm{S} \mathrm{cm}^{-1}\end{array}$} & \multirow{2}{*}{$\frac{\mathbf{N O}_{\mathbf{3}}{ }^{-}}{\mathrm{mgN} \cdot \mathrm{dm}^{-3}}$} & \multirow{2}{*}{$\frac{\mathrm{NH}_{4}{ }^{+}}{\mathrm{mgN} \cdot \mathrm{dm}^{-3}}$} & \multirow{2}{*}{$\frac{\mathbf{P O}_{4}{ }^{{ }^{3-}}}{\mathrm{mg} \mathrm{PO}_{4} \cdot \mathrm{dm}^{-3}}$} \\
\hline & $\mathrm{mm}$ & dni & & & & & \\
\hline Styczeń & 45,3 & 22 & 4,89 & 27,18 & 0,389 & 0,305 & 0,023 \\
\hline Luty & 34,8 & 17 & 5,01 & 28,35 & 0,435 & 0,322 & 0,038 \\
\hline Marzec & 38,4 & 25 & 5,21 & 25,04 & 0,258 & 0,230 & 0,020 \\
\hline Kwiecień & 39,6 & 17 & 5,26 & 26,17 & 0,205 & 0,152 & 0,016 \\
\hline Maj & 47,4 & 9 & 5,57 & 23,82 & 0,173 & 0,128 & 0,011 \\
\hline Czerwiec & 61,6 & 11 & 5,60 & 18,37 & 0,072 & 0,106 & 0,010 \\
\hline Lipiec & 78,5 & 14 & 5,62 & 16,52 & 0,067 & 0,078 & 0,012 \\
\hline Sierpień & 65,9 & 13 & 5,60 & 13,80 & 0,052 & 0,081 & 0,010 \\
\hline Wrzesień & 45,2 & 17 & 5,54 & 15,02 & 0,079 & 0,090 & 0,011 \\
\hline Październik & 49,7 & 16 & 5,42 & 18,49 & 0,135 & 0,115 & 0,015 \\
\hline Listopad & 47.3 & 17 & 5,17 & 23,58 & 0,172 & 0,128 & 0,018 \\
\hline Grudzień & 52,6 & 15 & 5,09 & 25,09 & 0,248 & 0,182 & 0,021 \\
\hline \multicolumn{3}{|c|}{ Średnia } & 5,33 & 21,79 & 0,190 & 0,160 & 0,016 \\
\hline Razem 2011 & 606,3 & 193 & & & - & & \\
\hline
\end{tabular}


Średnia roczna wartość odczynu pH zebranych wód opadowych w okresie od 2008 do 2011 roku wskazywała na ich kwaśny charakter (tab. 1 - 4). Prawie w $90 \%$ pobranych prób wartość pH była niższa od 5,6, czyli od wartości odpowiadającej naturalnemu odczynowi wód opadowych [4, 18]. Opady atmosferyczne charakteryzowały się również zróżnicowaniem ilości pozostałych badanych wskaźników: $\mathrm{NH}_{4}{ }^{+}, \mathrm{NO}_{3}{ }^{-}, \mathrm{PO}_{4}{ }^{3-}$.

Wskaźniki zanieczyszczenia opadów były w okresie badań zróżnicowane, lecz nie wystąpiły wyraźne tendencje zmniejszania się czy też zwiększania badanych wskaźników. Jest to zgodne $\mathrm{z}$ brakiem wyraźnych tendencji zmian emisji zanieczyszczeń powietrza $\mathrm{w}$ regionie województwa zachodniopomorskiego [11-14, 19] jak i w Polsce, gdzie od roku 2003 emisja większości zanieczyszczeń pozostaje na zbliżonym poziomie [12-14, 19].

Źródłem zanieczyszczenia powietrza atmosferycznego na terenie miasta Międzyzdroje jest emisja substancji pochodzących z procesów spalania paliw stałych, ciekłych i gazowych w kotłowniach przemysłowych i usługowych oraz komunikacja drogowa. Istotnym źródłem zanieczyszczeń jest też tzw. niska emisja pochodząca z lokalnych kotłowni węglowych i domowych pieców grzewczych, w których spalanie węgla odbywa się w nieefektywny sposób najczęściej węglem tanim, który posiada niskie parametry grzewcze.

$\mathrm{Na}$ stan jakości powietrza w Międzyzdrojach mają także wpływ napływy zanieczyszczeń atmosferycznych z kierunków północno - zachodnich, przemieszczają masy powietrza głównie z obszaru portu w Świnoujściu. Podstawową funkcją Portu w Świnoujściu jest przeładunek zboża, rud, olejów, papieru, celulozy, drobnicy, węgla, żelaza [20, 21]

\section{WNIOSKI}

1. Średnia roczna wartość odczynu pH zebranych wód opadowych w okresie od 2008 do 2011 roku na terenie miasta Międzyzdroje wskazywała na ich kwaśny charakter.

2. $\mathrm{pH}$ w $90 \%$ pobranych prób była niższa od 5,6, czyli od wartości odpowiadającej naturalnemu odczynowi wód opadowych.

3. Badany opad atmosferyczny charakteryzował się zróżnicowaniem ilości pozostałych badanych wskaźników: $\mathrm{NH}_{4}{ }^{+}, \mathrm{NO}_{3}{ }^{-}, \mathrm{PO}_{4}{ }^{3-}$.

\section{Polskie Normy}

PN/C-04537.02. Oznaczanie rozpuszczonych ortofosforanów kolorymetryczną metodą molibdenianową z chlorkiem cynawym jako reduktorem.

PN/C-04537.09. Woda i ścieki. Badania zawartości związków fosforu. Oznaczenie fosforu ogólnego.

PN/C-04576.01. Badania zawartości związków azotu. Oznaczanie azotu w postaci amoniaku i jonów amonowych.

PN/C-04576.09. Oznaczanie azotu azotanowego metodą kalorymetryczną z p-fluorofenolem.

PN/C-04540.03. Badania wartości pH, kwasowości i zasadowości. Oznaczanie kwasowości i zasadowości mineralnej i ogólnej metodą miareczkowania wobec wskaźników.

PN/C-04632.03. Ogólne zasady pobierania próbek do badań fizycznych, chemicznych i biologicznych. Technika pobierania próbek.

PN/C-04632.04. Ogólne zasady pobierania próbek do badań fizycznych, chemicznych i biologicznych. Utrwalanie i przechowywanie próbek.

PN/C-06504. Przygotowanie roztworów buforowych. 


\section{References}

[1] Arnaboldi M., Meyers P.A., Palaeogeography, Palaeoclimatology, Palaeoecology 190 (2003) 257-271.

[2] Barik S. K., Purushothaman C. S., Mohanty A. N., Aquaculture Research 32 (2001) 819-832.

[3] Bowden K. F., Oceanic and Estuarine Mixing Processes. W: Riley J. P., Skirrow G. (eds.), Chemical Oceanography. London-New York-San Francisco, 1974, 1-41.

[4] (Red.) B. Walna, L. Kaczmarek, J. Siepak, Chemizm i oddziaływanie kwaśnych deszczy na środowisko przyrodnicze. Sesja naukowa 10 czerwca 1996. Wyd. UAM, Poznań-Jeziory 1996.

[5] Daniszewski P., International Letters of Chemistry, Physics and Astronomy 1 (2012) 6-12.

[6] Daniszewski P., International Letters of Chemistry, Physics and Astronomy 1 (2012) 13-16.

[7] Daniszewski P., International Letters of Chemistry, Physics and Astronomy 2 (2012) $42-45$

[8] Daniszewski P., International Letters of Chemistry, Physics and Astronomy 2 (2012) $46-52$

[9] Daniszewski P., International Letters of Chemistry, Physics and Astronomy 2 (2012) $35-41$

[10] Dojlido J. R., Chemia wód powierzchniowych, Wydawnictwo Ekonomia i Środowisko, 1995.

[11] Główny Inspektorat Ochrony Środowiska, Raport o stanie środowiska w Polsce 2008, Biblioteka Monitoringu Środowiska, 2010, 121 ss.

[12] GUS 2009. Ochrona środowiska, Główny Urząd Statystyczny, Warszawa.

[13] GUS 2010. Ochrona środowiska, Główny Urząd Statystyczny, Warszawa.

[14] GUS 2011. Ochrona środowiska, Główny Urząd Statystyczny, Warszawa.

[15] Hermanowicz W., Dojlido J., Dożańska W., Koziorowski B., Zerbe J., Fizyczno-chemiczne badanie wody i ścieków, Arkady, Warszawa 1999.

[16] Jóźwiak M., Kozłowski R., Przegląd Geologiczny 53(11) (2005) 1059-1060.

[17] Krzysztofiak L., Mackiewicz A., Romański M., Krzysztofiak A., Stankiewicz M., Chemizm opadów atmosferycznych, Raport Wigierskiej Stacji Badawczej ZMŚP 2003, www.wigry.win.pl/monit2007/index.htm.

[18] Leśniok M.,. Zanieczyszczenie wód opadowych w obrębie Wyżyny ŚląskoKrakowskiej. Wyd. UŚl, Katowice 1996. 
[19] Ochrona Środowiska, GUS Warszawa, 2003-2008.

[20] Port Świnoujście. Urząd Morski w Szczecinie. 2008

[21] Port w Świnoujściu - nabrzeża. Zarząd Morskich Portów Szczecin i Świnoujście SA. 2009.

[22] Vollenweider R. A. Scientific fundamentals of the eutrophication of lakes and flowing waters, with particular reference to nitrogen and phosphorus as factors in eutrophication. DAS/CSIO/68.27, OECD, Paris 1968, ss. 192.

[23] Vollenweider R. A., Scientific fundamentals of the eutrophication of lakes and Following waters, with particular reference to nitrogen and phosphorous as factors in eutrophication. OECD, Environment Directorate, Paris 1971, pp. 27, 1-61.

[24] Vollenweider R. A., Global problems of eutrophication and its control. Symp. Biol. Hung., 1989, pp. 38, 19-41,

[25] Zestaw Norm - Woda i ścieki. Wyd. Normalizacyjne Alfa - Wero. Warszawa 1999. 